\title{
Gender Role in Saudi Arabian Female High School English Textbooks
}

\section{Traveller 1 and Traveller 2}

\author{
Waleed B. Al Abiky ${ }^{1}$ \\ ${ }^{1}$ College of Education, Curriculum and Instruction Department, Qassim University, Saudi Arabia \\ Correspondence: Waleed Al Abiky, Associate Professor of Foreign Languages, Qassim University, Saudi Arabia
}

Received: February 10, 2019 Accepted: March 12, 2019 Online Published: March 15, 2019

doi: $10.5539 /$ elt.v12n4p96

URL: https://doi.org/10.5539/elt.v12n4p96

\begin{abstract}
In an era of rapid and sustainable alterations, Saudi Arabia are now going through transformation in gender roles and opportunities. The current study aimed to investigate the gender roles in the two major English language textbooks widely used by Saudi female high school students, namely Traveller 1 and Traveller 2, which has been taught since 2013. To achieve the study goals, a mixed method was used; Content Analysis and a compiling quantitative data in which the corpus of the two English textbooks were analyzed and frequencies and percentages of gender appearances and activities were also calculated. The major findings of the study are 1) the textbooks contained some obvious gender bias and imbalance; 2) males were predominant whereas females were completely absent or marginalized; 3) females' pictures and participations in dialogues were very limited; 4) dialogues were largely male-male predominant and were about various topics; 5) males signed to gender roles significantly higher and more aggressive; 6) in contrast, females had weaker roles and never shown as symbolic or even significant social figures.
\end{abstract}

Keywords: gender role, Saudi female students, high school, English textbooks

\section{Introduction:}

Saudi Arabia is now facing some sustainable alterations in many levels especially with female roles and opportunities. For the first time in its history, females in Saudi Arabia are now allowed to drive and participate independently in social activities and careers. As a result, studying gender roles and inequality is increasingly becoming an important topic to address.

Like behaviors and norms, gender roles are often constructed throughout many social and cultural agents such as family, friends, schools, media, and worship places and so on (Corrado, 2009). For females in particular, gender roles are also shaped by traditional messages passed from families, schools environments and policies (Atli, 2017). Schools' textbooks, moreover, have been found highly significant sources as well. Evans and Davies (2000), for instance, clearly pointed out that textbooks that students, males or females, study, read and discuss in schools have surely long lasting effects on students' social roles, lives and activities as they would perceive the social world through gender depictions and roles shown and embedded in the textbooks (Yeung, 2013).

Aside from different perspectives, World Health Organization (WHO) differentiates and draws the lines between gender and 'sex'. WHO (2014) defines gender as the socially and culturally constructed actions, behaviors, roles and activities that a certain society in a specific culture considers normal, expected or appropriate for men and women. On the other hand, WHO defines sex as inborn biological origins that differentiates between males and females. As a result, gender is not innate or inherited but rather socially constructed behaviors, manners and expectations for each gender specific males and females.

As for the gender roles in English textbooks in Saudi Arabia, the current study adopts the Oxford dictionary definition of gender role which was defined as "the role or behavior learned by a person as appropriate to their gender determined by the prevailing cultural norms". As a result, gender role is not something we are born with or have, but rather learned, constructed and practiced.

There are indeed a few, if any, studies that looked at the gender roles in these textbooks especially for female Saudi high school students. The current study investigates the gender roles and representations in freshmen EFL 
high school female students' textbooks, namely Traveller 1 and Traveller 2, published by MM publications and authored by H.Q. Mitchell \& Marileni Malkogianni. These textbooks have been the major textbooks for female Saudi students since 2013 and are still as such till now.

\section{Importance of the Study}

School curriculum are indeed significant agents that construct gender images, roles and representations (Corrado, 2009; Chapman, 2008). In Saudi Arabia, female high school students spend around (7) hour each day at school which would surely have some long lasting effects on them. However, Chapman (2008) warned from possible gender bias, imbalance and misrepresentation embedded in schools' textbooks. The current study becomes more significant with English language textbooks because learners of a foreign language often tend to use the same names, practice the same roles and imitate the same dialogues' contents and use theme frequently in activities and assignments. This usage of names and content would definitely affect female students' self-conscious (Zografou, 1990; cited in Sunderland, 1994a).

Moreover, studying gender roles becomes more important in the textbooks for female teenagers who are still developing and experiencing many rapid changes in their bodies, emotional and psychological beings. Porreca (1984), for example, highlighted the danger especially on females emotional and well being when they do not appear properly and sufficiently in the text and/or illustrations of textbooks as often as males. Porreca explained the hidden messages and what it means for females to omit or limit their presences in EFL textbooks by stating that 'women's accomplishments, or that they themselves as human beings, are not important enough to be included' (p. 706).

Moreover, with 2030 Saudi Arabian vision, which was enacted in 2016, females' empowerments are important part of it. For instance, women participation in the labor force was set to raise from $22 \%$ to $30 \%$. As a result, investigating the gender roles and representations are worthy to strive for a more stable and better society.

\section{Purpose of the Study}

The current study aims to investigate gender roles and representation in the two English language textbooks of freshman Saudi female high school students, namely Traveller 1 and Traveller 2, which has been taught since 2013. Moore (2007) stated that students at school age often trust what they read in the textbooks which would as a result have long lasting impacts on students. Porreca (1984) stated that this is also true with younger students who tend to trust the printed words and not to question or doubt what they see and read as adullts often do.

Little or nothing is known about the gender roles in English textbooks used and taught in female high schools, and this study is trying to fill the gap and shed a light on this.

\section{Research Questions}

The current study is to answer the following main question:

How gender role is represented in Saudi Arabian female high schools' English textbooks Traveller 1 and Traveller 2?

And in order to answer this question, the study tends to answer the following three sub-questions:

1) How gender role is distributed among images and names throughout these textbooks?

2) What are the gender social roles for male and female characters?

3) How the discourse of male and female character is represented in the textbook's dialogues uni- or multi-gender dialogue?

\section{Theoretical Background}

It was in 1981, when Sandra Bem officially introduced the Gender Schema Theory in which an individual develops, practices, and maintains the gender schema in any given society. The theory is a cognitive process that explains how an individual becomes associated with a specific gender type in a given culture and behave in a line with it. In general, individuals learn about the gender roles from multiple mains and sources such as family, child raising, media, and schools' textbooks. Bem (1981) clearly states that there will always be individual differences in the degree to which individuals stick to those schemata.

Upon developing the gender schema, an individual in early age starts to learn the characteristics and behaviors appropriate and expected for a given sex. This process of learning is usually advanced and maintained by a variety of social agents such as parents, peers, religious places, and schools' textbooks which all deeply reinforce the gender role. Individuals, moreover, tend to adjust their behaviors to align with their gender role. In fact, the gender role is often reinforced through multiple venues and occurs "as a result of countless subtle and not so 
subtle ways" (Jakob, 2011).

In addition, most scholars have agreed that local environments and other venues of everyday social interactions such as homes, schools and religious places are the most powerful ways to construct the gender roles (Riegle-Crumb \& Morton, 2017). Those places are usually the first venues to construct gender roles and 'subsequently remind' individuals of what is appropriate and expected norms and behaviors of a certain gender (Risman, 2004).

\section{Literature Review}

It is widely known that by the time children start school, they begin to develop a clear understanding of gender roles, differences and appearances. Parental interactions, family relatives, media programs are just venues for children to construct their gender roles in early ages. Parke and Gauvain (2009) stated that as students' progress in school, their understandings and practices of gender roles encounter radical changes; they start to assimilate a wide verity of approaches to gender roles even with a little gaudiness of their teachers and parents.

Hazel (2014) highlighted the importance of schools' textbooks in shaping and constructing the students' gender roles. Hazel explained that students by large tend to take the content of the textbooks for granted and rarely challenge or even question the knowledge and the characters' roles embedded in these textbooks. As a result, Luk (2004) clearly underlined the huge effects of school textbooks on students' attitudes and social roles in the society in which these roles can greatly be associated "and/or transformed with what is conveyed in the textbooks." (p. 3).

Unlike males who usually need to strive to become men, females become real women by the time their natural biological changes occur, namely menstruation. Vandello and Bosson (2013) stressed the fact that textbooks are one of the most powerful factors not only in shaping the gender roles, but also in shaping the self-concept. As a result, Positive depiction of the gender roles for females in those textbooks are essential (Marsh \& O'Mara, 2008).

Tao (2008) warned of gender undervalue or false stereotypes portrayed in schools' textbooks because students will definitely grow up with what they study and learn in the textbooks and absorb their gender roles and false stereotypes. What female students see and learn in schools textbooks about their gender roles will more likely transfer to their social lives. Yeung (2013) also claimed that the way gender roles are presented in the textbooks would affect students' social, domestic, and professional careers and choices as students would likely think that this is what they are confined and expected for them to do.

Moreover, illustrations for any foreign language books are essential. Porreca (1984) argued that we need to be alert from illustrations' biases or misusage imbedded in those textbooks because of their hidden, harmful and long lasting impact. Porreca explained that:

When females do not appear as often as males in the text (as well as in the illustrations which serve to reinforce the text), the implicit message is that women's accomplishments, or that they themselves as human beings, are not important enough to be included (706).

In her interesting study, Sunderland (1992) examined the gender representation in EFL classroom and highlighted the potential affect of gender representation in EFL textbooks on students not only as language learners but also their gender roles in life. Sunderland found that the effects can be in one or more of the three ways: 1) textbooks as agents of socialization which can have an 'unconscious influence' on students and audience; 2) students could become demotivated or marginalized and their learning is affected when they find that their gender characters in the textbooks have limited or are offended or made to feel marginalized; 3) models of language can become classroom regular practice (p. 86).

Evans and Davis (2000) investigated the portrayals of men and women in the reading textbooks of $1^{\text {st }}, 3^{\text {rd }}$, and $5^{\text {th }}$ grade students in the United States focusing deeply on the personality traits of the main characters in each of the reading passages. The study found that males were often portrayed as significantly more aggressive and competitive than females. The study, moreover, found that males were significantly less likely to be described in relation to emotional traits such as affectionate, emotionally expressive or tender.

In addition, Moore (2007) examined gender representation in EFL textbooks used in Russia, and found that there were many gender biases and imbalances in two aspects: gender assignment to roles, and dialogues meant for conversational practice. She also found that unlike male-male dialogues, female-female dialogues were limited with few topics discussed.

Yeung (2013) stressed the fact that textbooks which students study, practice and discuss could instill some values, 
beliefs, or attitudes towards gender roles and expectations or even replace them. More importantly, Yeung argued that problematic or unclear perceptions about gender roles presented in textbooks could and would affect students' lives, academic or professional choices.

In her study about the women employment in Saudi Arabia, Al Munajjed, (2010) argued that the educational system in Saudi Arabia had not been successful enough in terms of preparing females for new roles or even new jobs positions. Moreover, until recently, females in Saudi Arabia were not allowed to enroll in some academic majors such as engineering, political science, and petroleum in public universities (HRW, 2008). Consequently, Saudi females largely limited themselves to specific academic majors and types of jobs. In the academic year of 2007, for instance, $93 \%$ of Saudi female university graduates were majoring in either education or social science which would restrict them to traditional work forces and prevent them from working in private sectors (Al Munajjed, 2010).

Moreover, Hamdan (2010) analyzed a series of English language textbooks used in Jordan and found that males dominated the majority of jobs in which $79 \%$ of jobs appeared in the textbooks were occupied by men. He also concluded that this type of bias portrayed males as the dominant characters of the labor market although women in Jordan nowadays are working in different kinds of positions such as political parliament, police officer, and even taxi drivers.

However, many demographic changes are now taking place rapidly in Saudi Arabia, especially for females. Kucinskas (2010) found that regardless of religious beliefs, social and economic status, Saudi young generation, females in particular, are now seeking more equality and hope for more gender egalitarian. As a result, new fields of work are now opening for women such as retails, customer services, and industries (Yusuf et al., 2015).

\section{Methods}

The current study aimed to investigate the gender roles in a corpus of two major English textbooks used for female Saudi Arabian high school students, namely Traveller 1 which is students' first semester textbook and Traveller 2 in the second, in the school year 2017-2018. These textbooks were published by MM Publications in the UK and authored by H. Q. Mitchell and M. Malkogianni. As most of EFL textbooks in Saudi Arabia, each textbook contains four modules which covers various topics such as youth culture, going places, diversity, and good job.

All English teachers in Saudi Arabia were required to cover and teach every module in those textbooks. Content Analysis was the main method used for the study in which those textbooks were analyzed and examined. However, a compiling quantitative data was also used in which frequencies, numbers and percentages of gender appearances and activities were calculated and analyzed. The analysis was carried out using two stages.

\section{Stage I: Analysis of illustration and texts}

All pictures, texts and dialogues in the textbooks were counted and analyzed. Quality of discourse and dialogues attributed to male and female characters were also considered.

\section{Stage II: Analysis of names and word distribution using WordSmith 7.0}

The respective textbooks were converted to text file format (.txt), and then analyzed using WordSmith 7.0 and names were identified and studied further.

\section{Results}

The results of the current study were based on the content analysis and a quantitative description of a corpus of two major English textbooks widely used and studied by the $1^{\text {st }}$ year high school Saudi female students: Traveller 1, students' textbook for the first semester which consists of 98 pages, and Traveller 2, for the second semester consisting of 83 pages. In analyzing those textbooks, there are mostly four aspects that present gender specific roles: 1) pictures or illustrations of human gender figures, 2) names addressing the main character(s), 3) social gender roles, and 4) dialogues that reflect a daily social talks or activities.

In most, or may be all, English language textbooks in Saudi Arabia public schools, genders are mostly represented by some or all of these sources or agents. Table 1 displays the frequencies of these four aspects throughout the two textbooks. 
Table 1. Overview of gender and its representation in Traveller $1 \& 2$

\begin{tabular}{llll}
\hline Source & Traveller 1 & Traveller 2 & Total \\
\hline Pictures & 33 & 39 & 72 \\
Names & 46 & 49 & 95 \\
Social roles/professions & 17 & 28 & 45 \\
Dialogues & 15 & 16 & 31 \\
Total & 111 & 132 & 243 \\
\hline
\end{tabular}

Table 1 indicates the distribution of gender specific among various sources used for gender roles presentation in these textbooks. Moreover, the above table shows that gender roles' sources or venues weighted more in Traveller 2, the textbook of the second semester. Names whether of males or females were in the highest frequency while dialogues whether uni- or multi- gender came the least.

\subsection{Answer of the $1^{\text {st }}$ Sub Question}

In most English language teaching books, pictures or illustrations of human beings or objects are essential part to clarify meanings, identities, grammar roles, and vocabularies. Pictures or illustrations of objects not clearly and directly include gender specific or human beings were excluded. Moreover, most of the human being images are identified and associated with names.

Furthermore, nouns in any English language textbook are considered crucial elements of the curriculum which students always use to imitate, give examples and familiarize themselves with nouns in the target foreign language. The following table displays the number of illustrations and names related to gender specific.

Table 2. Gender specific pictures and nouns in Traveller $1 \&$ Traveller 2

\begin{tabular}{ccccccc}
\hline Source & \multicolumn{2}{c}{ Pictures } & \multicolumn{2}{c}{ Names } & \multicolumn{2}{c}{ Total } \\
& M & F & M & F & P & N \\
\hline Traveller 1 & 33 & 0 & 40 & 6 & 33 & 46 \\
Traveller 2 & 38 & 1 & 43 & 6 & 39 & 49 \\
Total & 71 & 1 & 78 & 12 & 72 & 95 \\
\hline
\end{tabular}

As the above table indicates, male presence in those textbooks was predominant. Huge and obvious gap between the two genders specific is reflected. Unlike males, females' pictures or images were completely absent. In fact, there was only one female picture throughout the whole year textbooks. Moreover, despite the fact that these textbooks were used and studied by female high school students, the pictures in the textbooks were uni-gender in which males' images were the only gender specific included. Males in various ages, different cloths, multiple nationalities and professions were the ways in which males were presented in these textbooks.

Furthermore, $58 \%$ of males' pictures in Traveller 1 were heavily clustered in the first unit titled youth culture, whereas it was spread more evenly throughout Traveller 2. More interestingly, females' images were absent even in situations that were or could be connected to them such as eating in a restaurant, meeting new people and youth culture.

Moreover, as the above table clearly displays, names of males outnumbered the females; in fact, the comparison is not even exist. Eighty Six percent of names used in the whole year textbooks were names of males whereas females' names were only 14 percent despite the fact that those textbooks were taught and studied by females. This clearly shows the gender bias and imbalance in favor to males.

\subsection{Answer of the $2^{\text {nd }}$ Sub Question}

Gender roles were clearly embedded in these textbooks. They were spread around the textbooks' modules and students were definitely asked to practice them in the lessons' activities. Table 3 displays the types, distributions and frequencies of gender roles for both males and females. 
Table 3. Gender role types and distributions in Traveller $1 \& 2$

\begin{tabular}{|c|c|c|c|c|c|c|}
\hline & \multicolumn{2}{|c|}{ Traveller } & \multicolumn{2}{|c|}{ Traveller2 } & \multirow[t]{2}{*}{ Total } & \multirow[t]{2}{*}{ Rank } \\
\hline & M & $\mathrm{F}$ & M & $\mathrm{F}$ & & \\
\hline 1. Friend & 4 & 1 & 6 & 1 & 12 & $1 \mathrm{st}$ \\
\hline 2. Winter & 1 & 0 & 0 & 2 & 3 & 6th \\
\hline 3. Students* & 4 & 0 & 4 & 1 & 9 & $3 \mathrm{rd}$ \\
\hline 4. Parents (Dad /Mam) & 1 & 0 & 0 & 0 & 1 & 8th \\
\hline \multicolumn{7}{|l|}{ Grand father } \\
\hline 5. Husband/wife & 1 & 0 & 3 & 0 & 4 & 5 th \\
\hline 6. Son/daughter & 1 & 0 & 2 & 1 & 4 & 5 th \\
\hline 7. Farmer /business man & 0 & 0 & 2 & 0 & 2 & 7 th \\
\hline 8. Traveler / Explorer & 7 & 0 & 3 & 0 & 10 & 2 nd \\
\hline 9. Athletes & 3 & 0 & 2 & 0 & 5 & 4th \\
\hline 10. Chief & 0 & 0 & 0 & 1 & 1 & 8th \\
\hline 11. M. Doctor/ Poets/ & 1 & 0 & 0 & 0 & 1 & 8 th \\
\hline \multicolumn{7}{|l|}{ Life guard/ Fire fighter/ } \\
\hline \multicolumn{7}{|l|}{ Entertainer } \\
\hline 12. Rescue/ Factory worker & 2 & 0 & 0 & 0 & 2 & 7th \\
\hline Total & 26 & 1 & 21 & 6 & 54 & \\
\hline
\end{tabular}

* graduate students included and there is one male in each textbook.

As the above table shows, a total of (54) gender social roles embedded in those textbooks; these roles were repeated and spread throughout the textbooks. However, there were gender biases and imbalances and they appeared mostly as a single gender role. For instance, having or being a friend was the most recurring social role imbedded in those textbooks with the highest frequency. However, despite the fact that those textbook were taught and studied by females, almost 80 percent of those friendships were single gender and in between two or more males whereas females friendships were very limited. In fact, there were only two occurring friendships between females once in each semester. This finding put the textbook under scrutiny since there was no logical or comprehensive pedagogical reason for doing as such.

In addition, as shown in the above table, there were some highly frequent social roles pertained predominantly to gender specific unfairly. For instance, although being a student or studying in general is for males and females alike in many, if not all, countries around the globe, it has been largely and mainly attributed to males in these textbooks. Ninety five percent of social role as a student was confined to males only whereas female students appeared only once in the whole year, in Traveller 2. This is differently an educational flaw which is hard to justify, understand or even accept. This finding could be a practical example of what Porreca (1984) warned about its harmful implicate messages on females, especially teenagers, when they feel dependant and not being successful or even independent human beings in the society.

\subsection{Answer of the $3^{\text {rd }}$ Question}

Dialogues are important foundations in every foreign language textbooks because they present the target language in use. Focusing mainly on dialogues themselves, learners can learn quicker, use them effectively in writing and assimilate the way natives of any foreign language speak and carry on a daily conversation. In these studied textbooks, there were around (32) dialogues ranging from uni-gender dialogue to multiple-gender ones. Table 5 shows the total number of dialogues and how they are distributed. 
Table 4. Dialogues gender specific in Traveller $1 \& 2$

\begin{tabular}{lllll}
\hline Source & $\mathrm{M} / \mathrm{M}$ & $\mathrm{F} / \mathrm{F}$ & $\mathrm{M} / \mathrm{F}$ & Total \\
& & & $\mathrm{F} / \mathrm{M}$ & 16 \\
\hline Traveller 1 & 15 & 1 & 0 & 16 \\
Traveller 2 & 13 & 0 & 3 & 32 \\
Total & 28 & 1 & 3 & \\
\hline
\end{tabular}

As the above table reveals, the number of dialogues started or carried by males only were predominant and more frequent than that of females. In the textbooks, males were almost always the ones to start and carry on the conversation with another male partner. Females' dialogues were absent where there was only one dialogue done by female and it was short too.

Dialogues, moreover, were about various topics such as sports, studying, traveling, asking for directions, traveling and exploring. However, most of the dialogues were uni-gender and between males. The multi gender dialogues were very minimal and appeared only in the Traveller 2.

\section{Discussion and Conclusion}

In general, the study's findings clearly revealed the predominant roles, names, pictures and dialogues of males throughout the entire textbooks. This might be seen as clear evidence of not only bias against females but also inappropriate for female students in high schools who were still not yet mature and were in the process of developing their gender roles along with their emotional, social and psychological developments.

The finding of the current study supports the finding of Moore (2007) in which not only gender bias in the EFL textbooks were clear and consistent throughout the textbooks, but also dialogues were uni-gender with no female involved in any dialogue. Moreover, as found in Evans and Davis (2000) study, the current study uncover the case in which males' presence were by far predominate and portrayed more aggressively as they treated as the significant characters.

Moreover, the finding of the current study did not match with the findings of Al Munajjed, (2010) in which the gender role of female in these textbooks did not reflect reality of females in Saudi Arabia nor in the target language. The role of students, for instance, were merely and exclusively limited to males while females were completely absent from any school related role.

The current study also supports the finding of Hamdan (2010) in which gender imbalances were obvious in the English textbooks he analyzed. Males in those textbooks dominated various jobs and controlled the work forces while women were marginalized and portrayed as having very limited roles. Bothe studies, furthermore, found that the gender roles and presentations in the studied English textbooks don't reflect the reality of women roles in Saudi Arabia or in the target language.

A longitudinal study might uncover hidden and deep effects of gender imbalances and bias embedded in those textbooks which Sunderland (1992) called 'unconscious influence'. In addition, female future choices and decisions regarding their academic majors, careers, and social roles might all be investigated and correlated to these imbalances. As Yeung (2013) argued that female choices and decisions would diffidently affect their choices and decisions in a way or another.

Moreover, further qualitative endeavors using interviews or focus group with female Saudi students might be useful to measure and cover the depth and breadth of effects for not being inadequately and improperly presented in the textbooks on them. By doing as such, females would have the chance to reflect on this, express their thoughts, feelings, and affects with real examples. As stated in many studies, the analysis of schools' textbooks in terms of gender roles are essential since the way gender roles are presented in the textbooks have a long lasting impact on students' future lives, careers and academic choices. As a result, major modifications and changes are indeed necessary for female English textbooks used in Saudi Arabia to insure a more fair and realistic representation of gender roles.

Furthermore, the gender imbalances should be considered as big educational flaws which are hardly justified. In fact, this is not reflecting the real situation not only in the target language society but also in Saudi Arabia and its 2030 vision. The vision, which has a clear political well and enforcement, empower females to be independent in all aspects of life to insure gender equality instead of imbalance. 
In conclusion, although the authors made some successful approaches in focusing on grammar and making English clear and easy to use, but they fail to avoid gender specific biases and imbalances despite the fact that the authors were themselves females. Human beings, students in particular, do not perceive things similarly. As a result, the gender roles fair or even appropriate distributions were clearly missing in these textbooks and need to pay more attention to. Immediate remedial steps and corrections should indeed be discussed and followed.

\section{References}

Al Munajjed, M. (2010). Women's employment in Saudi Arabia: A major challenge. Dubai, UAE: Booz \& Co. The Ideation Center. Retrieved from http://www.strategyand.pwc.com/media/uploads/Womens Employment_in_SaudiArabia.pdf

Atli, A. (2017). High School Students' Gender Role Receptions Regarding Various Professions. International Journal of Progressive Education, 13(3), 06-15.

Bem, S. L. (1981). Gender schema theory: A cognitive account of sex typing. Psychological Review, 88, 354-364. https://doi.org/10.1037/0033-295X.88.4.354

Corrado, C. (2009). Gender identities and socialization. In J. O'Brien (Ed.), Encyclopedia of gender and society. (pp. 357-365). Thousand Oaks, CA: SAGE Publications, Inc. https://doi.org/10.4135/9781412964517.n181

Chapman, T. K. (2008). Desegregation and multicultural education: Teachers embracing and manipulating reforms. Urban Review, 40, 42-63. https://doi.org/10.1007/s11256-007-0076-4

Evans, L., \& Davies, K. (2000). No sissy boys here: A content analysis of the representation of masculinity in elementary school reading textbooks. Sex Roles, 42(3/4), 255-270. https://doi.org/10.1023/A: 1007043323906

Hamdan, S. (2010). English-language Textbooks Reflect Gender Bias: A Case Study in Jordan. Advances in Gender and Education, 2, 22-26.

Hazel, C. P. (2014). Textbooks and genders: gender representation in teaching materials of liberal studies in Hong Kong (Doctoral dissertation). The University of Hong Kong, Pokfulam, Hong Kong.

Human Rights Watch (HRW). (2008). Perpetual minors: Human rights abuses stemming from male guardianship and sex segregation in Saudi Arabia. New York City, NY: Human Rights Watch. Retrieved from https://www.hrw.org/sites/default/files/reports/saudiarabia0408_1.pdf

Jakob, C. (2011). Gender as a practical concern in children's management of play Participation. In S. A. Speer, \& E. Stokoe. Conversation and Gender (pp. 296-309). Cambridge: Cambridge University Press.

Kucinskas, J. (2010). A research note on Islam and gender egalitarianism: An examination of Egyptian and Saudi Arabian youth attitudes. Journal for the Scientific Study of Religion, 49(4), 761-770. https://doi.org/10.1111/j.1468-5906.2010.01545.x

Luk, B. (2004). Gender roles in Hong Kong textbooks. Paper presented at the First International Conference on Gender Equity Education in the Asia-Pacific Region, November 25-27, 2004.

Marsh, H. W., \& O'Mara, A. (2008). Reciprocal effects between academic self-concept, self-esteem, achievement, and attainment over seven adolescent years: Unidimensional and multidimensional perspectives of self-concept. Personality and Social Psychology Bulletin, 34, 542-552. https://doi.org/10.1177/0146167207312313

Moore, E. (2007). Gender Representation in Russian EFL Textbooks. (MA Thesis, California State University, Long Beach).

Mitchill, H., \& Malkogianni, M. (2017). Traveller 1 English Language- KSA- Edition. MM Publications: London.

Mitchill, H., \& Malkogianni, M. (2017). Traveller 2 English Language- KSA Edition. MM Publications: London.

Parke, R. D., \& Gauvain, M. (2009). Gender Roles and Gender Differences. Child Psychology: A Contemporary Viewpoint (7th ed.). Boston: McGraw Hill.

Porreca, K. L. (1984). Sexism in current ESL textbooks. TESOL Quarterly, 18(4), 705-724. https://doi.org/ $10.2307 / 3586584$

Riegle-Crumb, C., \& Morton, K. (2017). Gendered Expectations: Examining How Peers Shape Female Students' Intent to Pursue STEM Fields. Front Psychol, 8, 329. https://doi.org/10.3389/fpsyg.2017.00329 
Risman B. J. (2009). From doing to undoing: gender as we know it. Gender Soc, 8(4), 429-450. https://doi.org/10.1177/0891243204265349

Sunderland, J. (1992). Gender in the EFL classroom. ELT Journal, 46(1), 81-91. https://doi.org/10.1093/ elt/46.1.81

Sunderland, J. (1994a). Introduction. In J. Sunderland (Ed.), Exploring gender. London: Prentice Hall.

Sunderland, J. (1994b). Pedagogical and other filters. In J. Sunderland, (Ed.), Exploring Gender. London: Prentice Hall.

Tao, B. (2008). Identifying and Combating Sexism in EFL Textbooks - with a case study into China. Educational Resources Information Centre. Retrieved September 13, 2018, from http://www.eric.ed.gov/ERICDocs/data/ericdocs2sq1/content_storage_01/ 0000019b/80/3e/4c/94.pdf

Vandello J. A., Bosson J. K. (2013). Hard won and easily lost: A review of synthesis of theory and research on precarious manhood. Psychology of Men \& Masculinity, 14(2), 101-113. https://doi.org/10.1037/a0029826

World Health Organization. (2014). Gender. Retrieved June, 26, 2014, from http://www.who.int/genderequity-rights/understanding/gender-definition/en/

Yeung, C. (2013). The representation of gender in junior secondary ELT textbooks in Hong Kong. University of Hong Kong. https://doi.org/10.5353/th_b5094918

Yusuf, N., Al-sharqi, L., \& Durrani, F. (March/April 2015). A determinant of healthy ageing women education in Saudi Arabia. International Business \& Economics Research Journal, 14(2), 355-366. https://doi.org/10.19030/iber.v14i2.9168

\section{Copyrights}

Copyright for this article is retained by the author(s), with first publication rights granted to the journal.

This is an open-access article distributed under the terms and conditions of the Creative Commons Attribution license (http://creativecommons.org/licenses/by/4.0/). 